649

\section{PARATHYROID HORMONE (PTH) AND MARKERS OF CALCIUM METABOLISM IN CHILDREN WITH CONGESTIVE HEART FAILURE}

\author{
A.A. Fattouh1, R.N. Said ${ }^{2}$, A.M. Nour El Din", \\ R.I. Ammar', D.A. $A h^{3}$
}

${ }^{1}$ Pediatrics, National Research Center, ${ }^{2}$ Pediatrics, Faculty of Medicine, Cairo University, ${ }^{3}$ Clinical and Chemical Pathology, National Research Center, Cairo, Egypt

Background: Parathyroid hormone ( PTH) regulates the content of calcium and exerts an effect on myocardial function. Abnormal secretion of PTH has been reported with depressed mechanical performance of the heart muscle.

Aim is to evaluate parathyroid function in patients with CHF due to dilated cardiomyopathy (DCM), measuring some different parameters of calcium metabolism.

Patients and Methods: A case- control study carried on 30 cases (20 males and 10 females) with congestive heart failure ( $\mathrm{CHF}$ ) having a mean age of $6.69 \pm 3.94$ years. They were recruited from Cardiomyopathy Clinic in Children Hospital Cairo University.. Cases were further classified into(i) Decompensated $\operatorname{HF}(n=18)$ ( NYHA III, IV) (ii) Compensated HF( $n=12)$ ( NYHA II) . Thirty healthy children ( matched age and sex) were enrolled to serve as control. Parathyroid hormone (PTH) and Osteocalcin (OC) were measured, in addition to total serum calcium, phosphorus, alkaline phosphatase, sodium and potassium.

Results: There is statistically significant lower serum calcium , osteocalcin and higher serum phosphorus levels in DCM cases compared to controls ( $P=0.0001,0.0001,0.002$ respectively). There was no statistically significant difference between cases and controls regarding serum PTH. i.e. normal PTH despite depressed calcium in DCM

Conclusion: Although three decompenstated CHF cases showed elevated Parathyroid hormone levels, (NS) PTH levels were normal inrest of cases. Significant hypocalcemia , hyperphosphatemia and reduction in serum Osteocalcin levels were noted in CHF patients. Whether, or not, these factors contribute to systemic illness that accompanies $\mathrm{CHF}$, including bone wasting, mandates further probing

\section{INVESTIGATION OF THE PROBABLE CAUSES OF SPECIFIC CHILDHOOD DISABILITIES IN EASTERN AFGHANISTAN (PRELIMINARY REPORT)}

\section{J.A. Nasir}

Environmental Health Protection Unit, Public Health Institution of Canton Sarajevo-Pediatrics Department Division, National Institute of Health Islamabad, Islamabad, Pakistan

Summary: To identify risk factors likely to cause developmental disabilities and to generate hypotheses for a further study of risk factors predisposing to disability and slow mental and physical development. Mothers and children attending/visiting the Sandy Gall's Afghanistan Appeal(SGAA) clinics inthe EastZone ofAfghanistan. The main outcome measures, developmental disabilities, cerebral palsy (CP), club foot, $\mathrm{CDH}$ and polio. Results, $37.5 \%$ of the disabilities were present at birth, $46 \%$ of the disabled children were born from parents who are 1st cousin which was confirmed by computing $x 2$ value, which is 10.87 with one degree of freedom. $58.3 \%$ of the disabled children were born from parents who lack antenatal care. $22.4 \%$ of the pregnant women in the defined population had antenatal checkups, and $97 \%$ of the mothers in the defined population are illiterate, $52 \%$ of the children found with CP specific and mental retardation. $25 \%$ were with delayed physical and mental development. $13 \%$ were with CPspecific and $10 \%$ were club foot. $2 \%$ of the children were visually handicapped, $9 \%$ with hearing impairment. $61 \%$ of children were from Nangarhar, $25 \%$ from Laghman and $14 \%$ from Kunar.

\section{1}

\section{THE SPECTRUM OF COMPATIBLE LANDRY-GUILLAIN-BARRE SYNDROME IN CHILDHOOD. A SINGLE REFERRAL CENTRES EXPERIENCE:AN ANALYSIS OF 48 CASES}

\section{E.U. Onyekwelu, Neurology}

\section{Paediatrics, Royal Victoria Teaching Hospital, Banjul, The Gambia}

Background / purpose: Although the association of neuropathies/infections was suggested historically, the first scholarly description was made by Landry in 1859. 